\title{
BENTONITE APPLICATIONS IN SIMPLE PURIFICATION OF BULK COOKING OIL AS ALTERNATIVE SOLUTIONS FOR HOUSEHOLD COST EFFICIENCY
}

\author{
Mira Meirawaty ${ }^{1}{ }^{*}$, Christin Palit $^{2}$, Dyah Ayu Setyorini ${ }^{1}$, Moehammad Ali Jambak ${ }^{1}$ \\ ${ }^{1)}$ Department of Mining Engineering, Faculty of Earth and Energy Technology, Universitas Trisaksi, \\ Indonesia \\ ${ }^{2)}$ Department of Geology Engineering, Faculty of Earth and Energy Technology, Universita Trisaksi, \\ Indonesia
}

\begin{abstract}
Utilization of Crude Palm Oil (Crude Palm Oil) in food cooking activities is a strong activity in Indonesian society, more than $80 \%$ of household activities use this type of oil to process food ingredients. The affordable price with a variety of packaging makes this type of cooking oil has many fans. A survey that has been conducted on residents of the Kalideres area with a total of 20 respondents stated that in addition to using new palm cooking oil in cooking activities, the majority of residents are also accustomed to using this oil used in cooking activities that require the deep-fried method. The quality of cooking oil is largely determined by the level of purity of the solution, the clearer the color of the solution, the better the quality, the darker the color of the solution indicates the presence of more impurities, the higher the saturated fatty acid emulsion, indicating poor cooking oil quality. This is what was raised in this community service (CS) activity, namely socializing alternatives to the use of purified bulk cooking oil. The purification material uses bentonite clay minerals which are heated and dissolved in a certain amount and duration of time which is able to maximize the adsorption power of impurities according to the natural structure of bentonite. CS activities carried out online include counseling and training activities for housewives in the economically densely populated Kalideres area. Through the socialization program for the purification of bulk cooking oil using bentonite clay minerals, it is hoped that residents will have an alternative to reduce the cost of processing food raw materials in a more effective and healthy way. This program is also expected to function as a medium to socialize the application of earth science in helping activities of daily living.
\end{abstract}

Keywords: Bentonite, Bulk Oil Purification, Crude Palm Oil (CPO)

\section{Introduction}

Kalideres Urban Village is administratively located in the city of West Jakarta, DKI Jakarta Province. With an area of $30.23 \mathrm{~km}^{2}$, this subdistrict is the largest area in West Jakarta, and

${ }^{*}$ E-mail: ali@trisakti.ac.id

Received: 2 September 2021

Revised: 15 September 2021

Accepted: 15 September 2021

DOI: $10.23969 /$ jcbeem.v5i2.4471 the population is the second largest after Cengkareng sub-district (BPS-Statistics of West Jakarta, 2020). As a densely populated area with a high economic rate, the Kalideres area is full of population and environmental problems. Some of the environmental problems that are often present in this area are: waste problems, flooding, clean water crisis and environmental pollution, slum settlements, illegal street vendors, and land use management. High population 
density and unequal levels of the economy trigger socio-economic problems that reduce the quality of meeting the needs of daily life.

The use of Crude Palm Oil in cooking activities for food ingredients is an activity that is thick in Indonesian society. The results of a survey conducted by (Martianto, 2005) stated that the average use of cooking oil in Indonesia was 23 grams per day, with $77.5 \%$ of household activities using bulk cooking oil for frying food. The last survey conducted on 20 residents of Kalideres showed that as many as 22 people (65\% of correspondents) used bulk cooking oil, or "jalantah", in their daily cooking activities. As used palm cooking oil that has been used many times, raw cooking oil shows poor oil quality, indicated by its dark color and foamy texture. The quality of cooking oil is largely determined by the level of purity of the solution, the clearer the color of the solution, the better the quality of the cooking oil. The darker the color of the cooking oil, indicating the presence of more impurities, the tendency for the emulsion to have higher levels of saturated fatty acids, which will certainly be harmful to health.

There are many ways that can be done to purify used palm cooking oil, including using rice, banana peels and even bleach to clear up the dark color of the solution. Some of these methods have been proven to be effective in clearing the dark color of cooking oil, but have not been proven to reduce the saturated acid content caused by repeated heating of used cooking oil (bulk oil). Currently in the market there is also bulk cooking oil that can be used directly for cooking activities, but because it has not been tested by BPOM, the quality and effect of using this oil on health is not known. This is what was raised in this community service (CS) activity, namely to socialize the role of Bentonite clay mineral as a purification material for bulk cooking oil, in accordance with the specifications of the speaker's expertise from the fields of geology and mining.

This CS aims to provide a solution for recycling used cooking oil in a simple way that does not endanger health. The results of CS can also be an alternative for residents to reduce the cost of processing food raw materials. Although there have been similar studies on the purification of used cooking oil using benthite material, this CS activity uses another approach in the form of simple oil processing that can be done in the kitchen of each resident's house. As an activity that socializes the role of natural materials to purify used cooking oil, this CS activity is an effective means of grounding the science of geology to be applied in daily life activities.

\section{Research Methodology}

CS activities are carried out for 1 day, namely on April 25, 2021 online starting at 09.00-11.00 via online zoom media. The participants consisted of residents of Kampung Rawa Lele, RT 004 / RW 007, Kalideres District, West Jakarta, DKI Jakarta Province. The target communities for this socialization are housewives $(60 \%)$, traders $(20 \%)$, students (10\%), employees (5\%), and community health center sanitarians $(5 \%)$. From the income level, as many as $65 \%$ of participants have a fixed monthly income of less than Rp. 300.000/month, $35 \%$ of participants have a fixed monthly income above Rp. 300.000/month. The population density survey can be seen from the questionnaire on the number of family members who live in one house, $60 \%$ of the participants live in one house with more than 5 families, and $40 \%$ have less than 5 family members.

This CS activity is one of a series of socialization activities that raises the role of bentonite clay minerals to assist daily living activities. The two main topics raised in this CS activity are the role of bentonite as a purification 
material for bulk cooking oil, and the application of bentonite in water filtration. Once the application of bentonite clay minerals, its affordable price is also a side that is highlighted in this socialization. The series of CS activities consisted of: delivering material on the topic "Mineral Bentonite as a solution to purify bulk cooking oil", interactive discussions between residents and a team of presenters, demonstration of bulk cooking oil purification through online video demos, questionnaire tests and polls, and door prizes given done at the end of the event.

\section{Research Location}

The location of the CS partner area is a densely populated residential area located in Kalideres District, West Jakarta, DKI Jakarta Province, with the location of the presenter being accessible as shown in Figure 1.

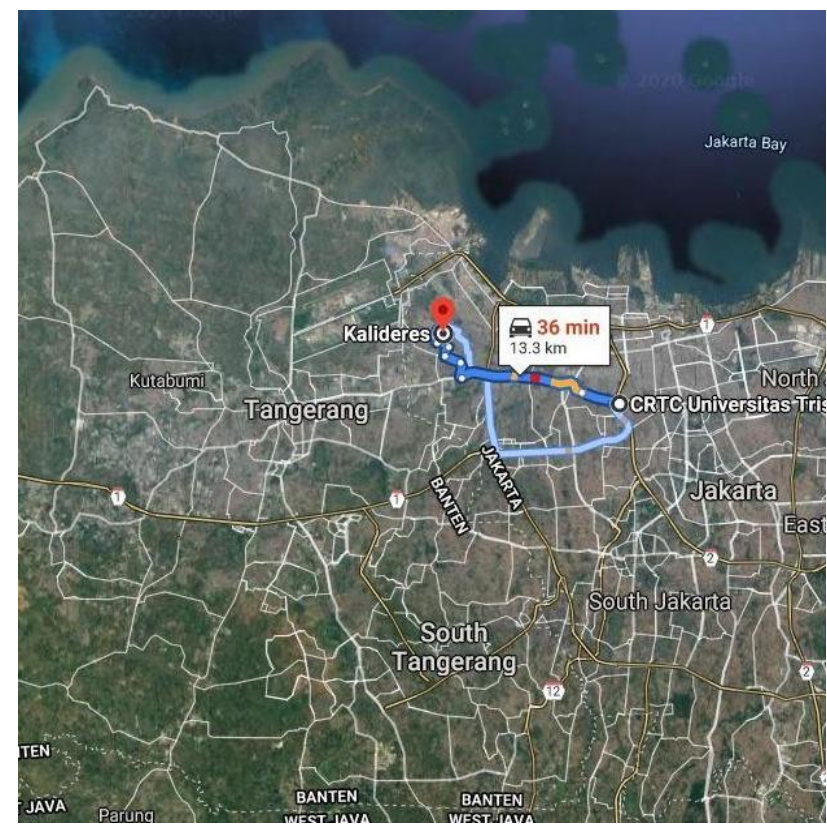

Figure 1. The availability of the CS location, namely Kalideres village from Universitas Trisakti (Utilization of Google Maps, 2021)

\section{Methods, Tools and Materials}

Related to the objectives to be achieved, this CS activity is carried out in several stages, namely:

Preparation of activities, including:

1. Permission procedure to the head of RT/RW (neighbourhood head/ head of hamlets)

2. Bulk cooking oil purification experiments, including:

- Preparation of bulk cooking oil and active benthonite adsorbent (bentonite $+\mathrm{H}_{2} \mathrm{SO}_{4}$ )

- Cooking oil + active bentonite is stirred and heated using a stirrer in the laboratory

- Cooking oil+active bentonite is stirred manually and heated manually on a gas stove

- Cooling and separation of cooking oil solution from bentonite clay and filtering on oil paper

- Test the quality of used cooking oil that has been clarified using physical parameters such as: color, level of turbidity, odor/taste

3. Implementation of activities, including:

- Polling filling (before CS event)

- Counseling on healthy and suitable cooking oil

- Description of the characteristics of the mineral bentonite and its various applications in life

- Demonstration and demonstration of bulk cooking oil purification through video demo

- Interactive discussion and Q\&A

- Filling out the questionnaire (after the CS event)

- door prize

The process of purification of road oil was carried out using 2 methods, laboratory experimental methods and manual experiments 
using simple kitchen utensils. Figure 1 shows the equipment used during the purification of crude oil in the Chemistry laboratory, namely equipment in the form of weighing equipment, measuring cups, and magnetic stirrer.
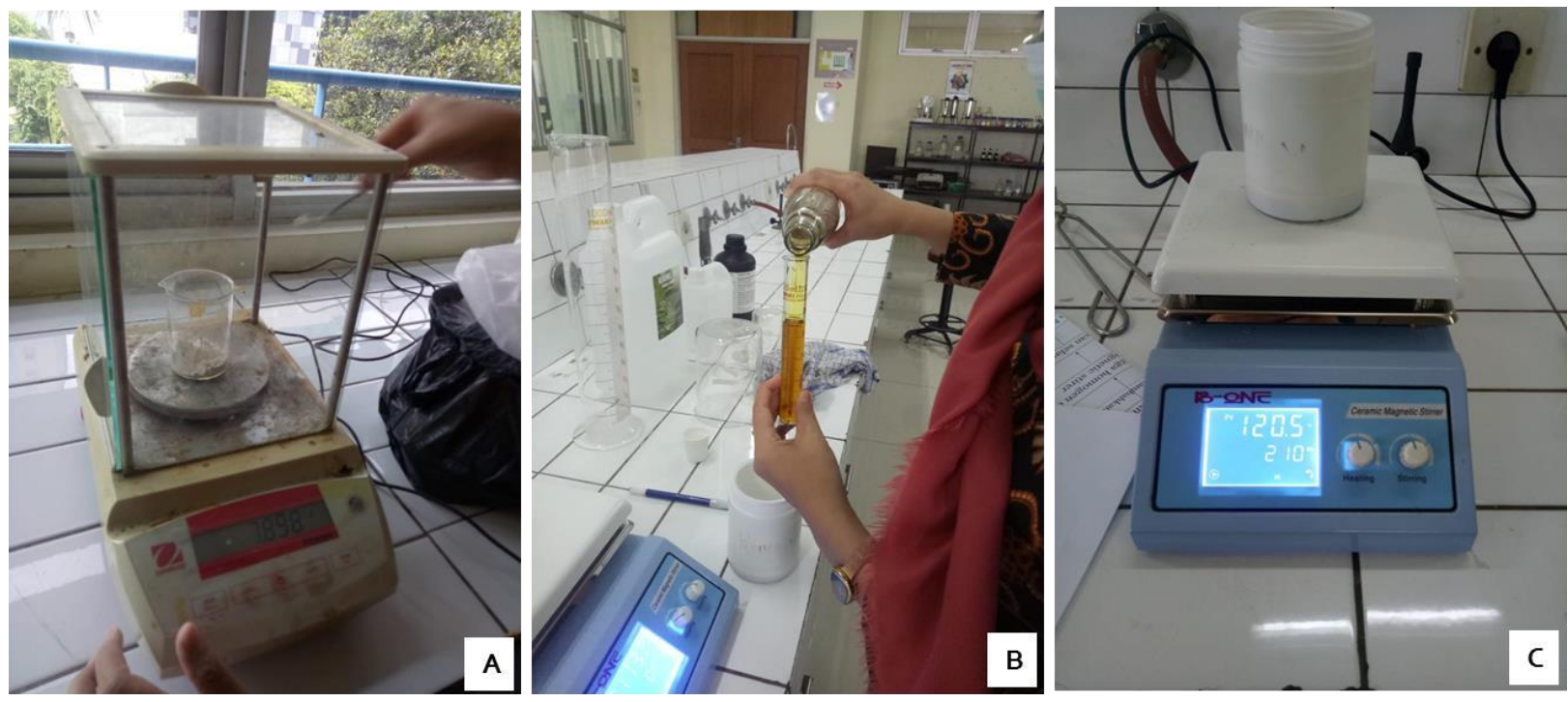

Figure 2. Laboratory equipment used during the oil clarification experiment, including weighing equipment (A), measuring cup (B), and magnetic stirrer (C)

\section{Result and Discussion}

The CS activity has been carried out online using a zoom platform that is connected to the poll application and online questionnaire. This CS activity is a multidisciplinary outreach activity that raises the natural character of bentonite clay whose crystal structure is layered, so it is very effective as an adsorbent material for impurities from solution. The event ran smoothly and interactively with online presentations interspersed with polling sessions and filling out questionnaires through the quiziz online application. At the end of the event, an electronic pulse voucher was given to 3 selected participants who were taken from the participants who asked questions. During the event, the participants looked enthusiastic as seen from the questions that came in during the discussion session and the results of the contents of the questionnaire which showed that the counseling materials had been well absorbed by the participants. Figure 3 shows the documentation of CS activities carried out online. 


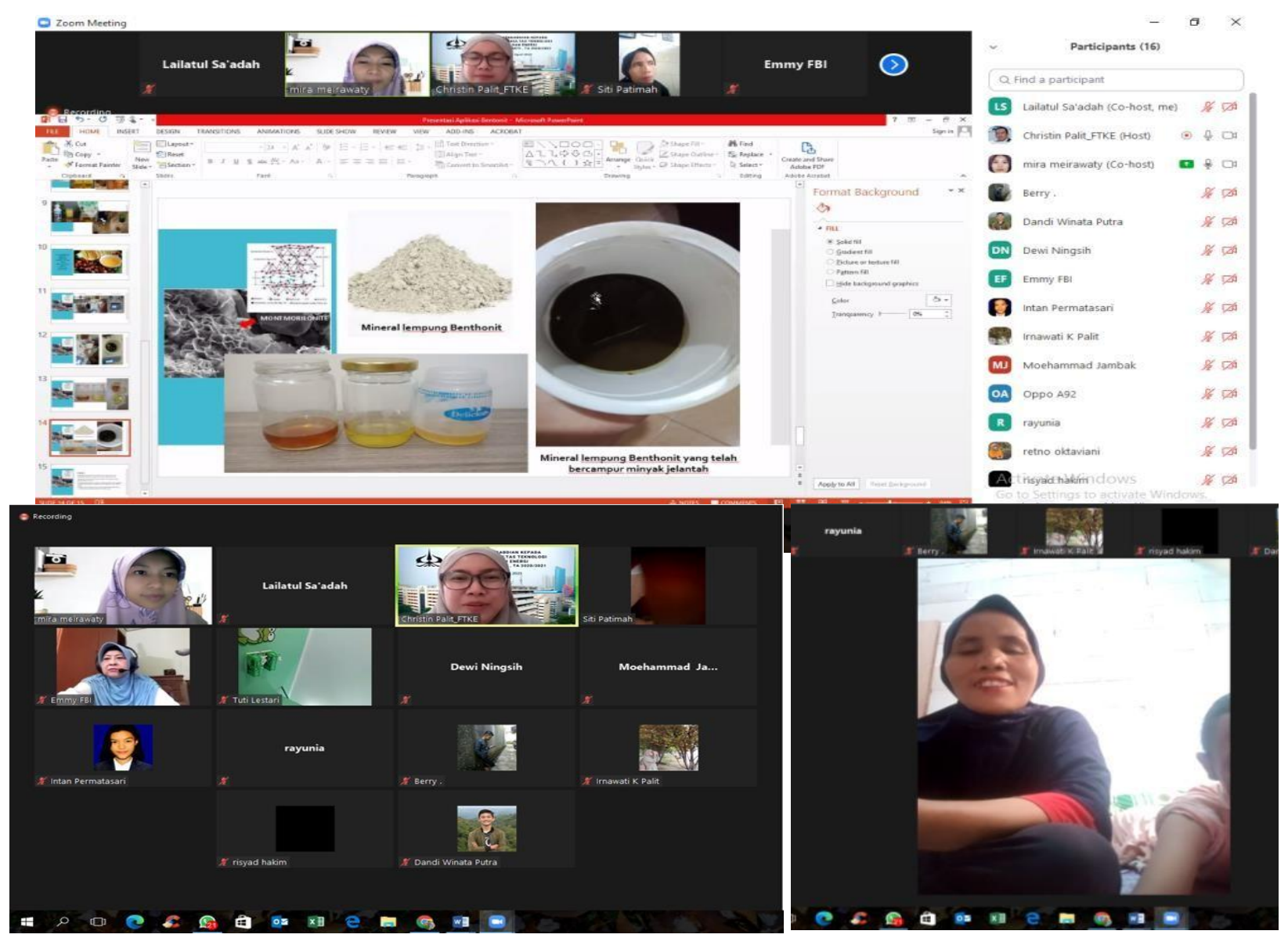

Figure 3. Documentation of CS activities during the material presentation and question and answer

Bentonite clay minerals are part of the smectite group which has a layered structure, will expand when dispersed into water, so it is very well used as an adsorbent material (Mukherjee, 2011). The results of research conducted by Darmadinata, M., et al (2019) showed that activated bentonite using $1.5 \mathrm{M} \mathrm{H}_{2} \mathrm{SO}_{4}$, the crystal surface area would increase so that the adsorption ability of the adsorbent was more optimal. The bentonite material used in this purification activity is bentonite clay that is not activated. But even so, engineering activities that only utilize the natural properties of bentonite as an adsorbent have shown significant results in changing the color of bulk oil from dark brown to clearer. The purification is done by mixing bentonite material with crude oil in a ratio of 1:5. After being mixed, the bentonite + crude oil solution was then stirred using a magnetic stirrer while heated for 60 minutes. The cooled solution is then left for 24 hours so that the coarse particles settle to the bottom of the solution. After the phase separation occurs between the liquid oil and the bentonite solids that tend to collect at the bottom of the solution, filtering is carried out using oil paper to separate the bentonite material that is still dissolved in the purified oil. 

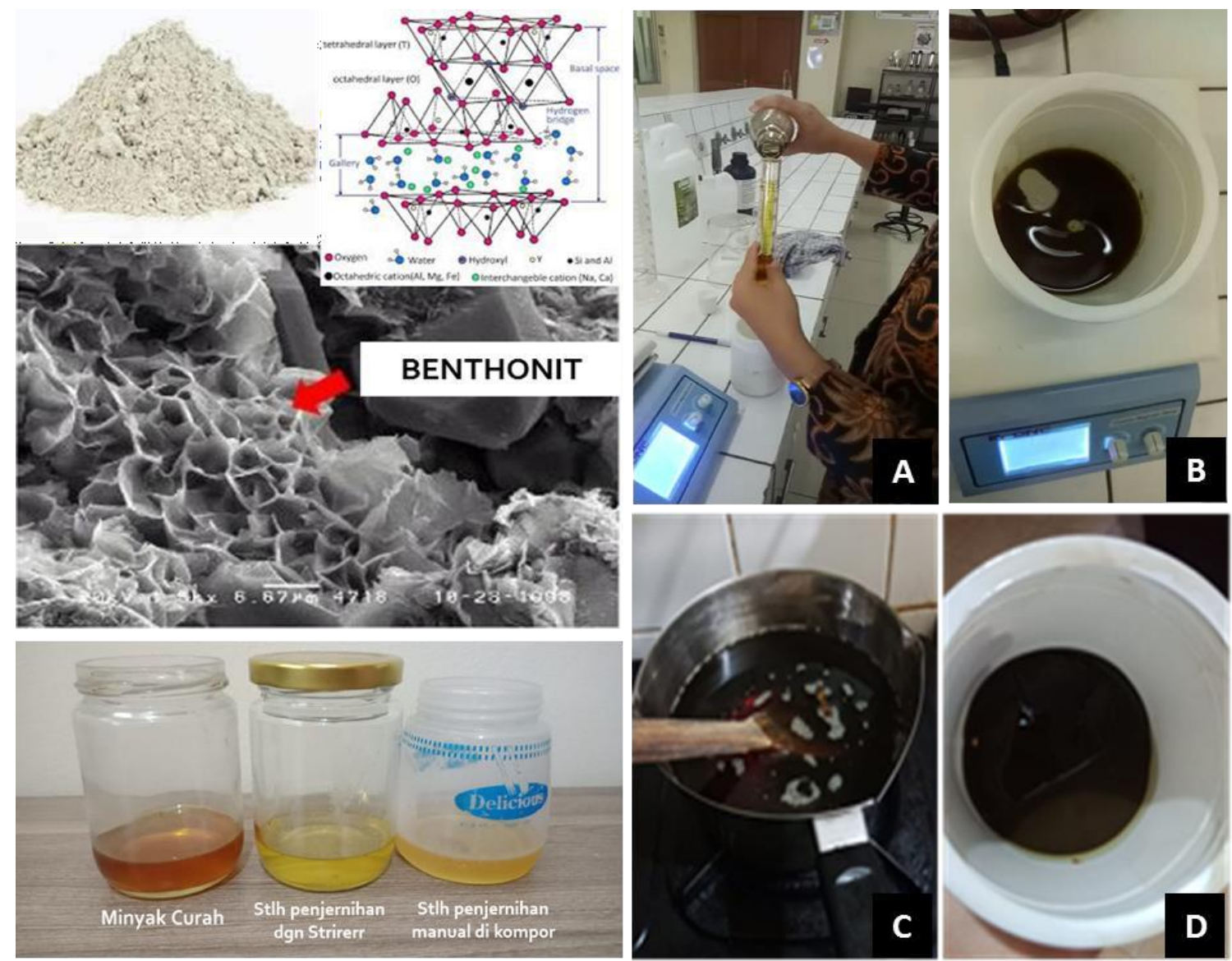

Figure 4. Cleansing activities of used cooking oil in the chemical laboratory (A, B), cleaning activities with manual stirring on the stove $(C, D)$, and comparison of the results

In addition to being carried out in the laboratory, a simpler manual purification activity is also carried out to see the effectiveness of the purification of the two different methods. This purification practice is simpler, namely mixing bentonite material and crude oil in a ratio of 1:10. Then the solution is heated on the stove while stirring for about 10 minutes. After the solution cools, it is then left for 24 hours to allow the separation of fractions between solids and liquids. Filtering using parchment paper was then carried out to clean the bentonite which was still soluble in the purified crude oil. Figure 4 shows the process of purification of raw cooking oil carried out in the laboratory, the purification of used cooking oil which is carried out manually on the stove, and a comparison of the results.

\section{Evaluation}

The success of this Community Service (CS) activity can be seen from the following two benchmarks:

1. Positive response from counseling and training participants; Participants' responses will be observed during the socialization activities. The questions that came in during the discussion session and the high enthusiasm during the event showed that the participants had given a positive response to the implementation of CS activities

2. Increased knowledge of participants after receiving counseling and training. The benchmark for increasing participants' knowledge and skills after socialization can be seen from the results of online questionnaires for CS participants. 
Correspondents consisting of housewives (60\%), traders (20\%), students (10\%), employees $(5 \%)$, and puskesmas sanitarians (5\%), were able to answer questionnaire questions related to the material correctly. . Participants also participated in the event and discussion enthusiastically, indicating that the purpose of the extension in the form of socializing the bulk cooking oil purification program had been achieved.

Another benchmark used during the CS implementtation is the online poll media. The results of the poll for the CS Program for Cooking Oil Purification with Bentonite CS participants (respondents) who participated in the poll were 20 people, with varying levels of education ranging from junior high school to undergraduate. The poll includes 2 (two) questions:

1. What cooking oil do you usually use for daily cooking?

a. Palm cooking oil : $100 \%$

b. Apart from palm cooking oil : $0 \%$

2. How often do you use bulk/used palm oil?
a. Often $65 \%$
b. Never $35 \%$

Table 1. Distribution of examples of the use of palm cooking oil

\begin{tabular}{|c|c|c|c|}
\hline \multirow{2}{*}{ Question } & \multicolumn{2}{|c|}{ Response (\%) } & \multirow{2}{*}{ Total } \\
\cline { 2 - 3 } & $\mathbf{a}$ & $\mathbf{b}$ & \\
\hline 1 & $100 \%$ & $0 \%$ & $100 \%$ \\
\hline 2 & $65 \%$ & $35 \%$ & $100 \%$ \\
\hline
\end{tabular}

Based on the poll results, a total of $100 \%$ of correspondents use palm cooking oil in their cooking activities, this is possible because the price is cheaper and easily available in the market. In addition to the results of a poll about the repeated use of palm oil for cooking, $65 \%$ of the respondents stated that they often used it and $35 \%$ of them never or only used it once. This is possible because of the high economic level or already aware of the dangers of using cooking oil repeatedly.

Then for questions:

"Have you ever heard of the process of purifying bulk palm cooking oil?"

This question was conducted 2 times, before and after CS socialization, the results showed different results:

Based on the results of the poll, it showed that after socialization on the purification of palm cooking oil with bentonite showed $100 \%$ understanding and knowledge knowing that bentonite, which is a type of clay mineral, can be used to purify used cooking oil. In the poll after the socialization event, the level of interest in applying this method after the event was also asked, only 10 people (50\%) stated that they would try this method. It is assumed that the method is still not practical and the materials used are not common materials so that it makes participants think twice about trying it.

\section{Activities Supporting and Inhibiting Factors}

The supporting factor for the implementation of this CS activity is the cooperation of the CS activity partners, which in this case is Mrs. RT and the residents of Rawa Lele Village, Kalideres, West Jakarta. The enthusiasm of the participants was also very visible during the activity, reflected in the active participation of the participants in answering the quiz questions as well as the various questions about the cooking oil purification method that were asked. Some housewives also criticize whether this clay mineral is an effective method to reduce saturated fat content in bulk cooking oil or not, and how to obtain it because this type of material is not available in general stores. 
The inhibiting factor is the lack of socialization of activities so that it has an impact on the number of participants who attend. The form of online/online activities is also constrained because not all residents are familiar with the "zoom" online platform, especially for the lower middle class people who are not too in touch with online electronic media. The professional background of the participants, consisting of housewives, employees, traders, sanitarians at the puskesmas and students, did not become an obstacle, instead the diversity of professions warmed the atmosphere during the discussion based on the varied topics of questions that came in.

Based on the results of the poll, it showed that after socialization on the purification of palm cooking oil with bentonite showed 100\% understanding and knowledge knowing that bentonite, which is a type of clay mineral, can be used to purify used cooking oil.

\section{Conclusion}

From the implementation of this CS activity, it can be concluded that:

1. The CS activity "Socialization of Bentonite Applications in Purification of Bulk
Cooking Oil" has been useful in adding insight and educating CS participants about the use of proper cooking oil. It can be concluded from the results of the questionnaire that showed changes in the knowledge of the training participants, from initially only $35 \%$ of participants knew about information on purification of bulk cooking oil until it increased to $100 \%$ of participants who understood the criteria for proper cooking oil and alternative purification using bentonite, after the CS activity was carried out. Of the $100 \%$ who are aware of the importance of using cooking oil according to health standards, only $50 \%$ are interested in trying alternative techniques using bentonite, this shows that the purification method is still not practical to implement, it is necessary to explore the application of appropriate technology that makes it easier for residents to access and use it. in daily routine.

2. The results of the questionnaire given to 20 respondents from Kalideres represent a description of the behavior of the Indonesian population, some of whom are accustomed to using used cooking oil for cooking

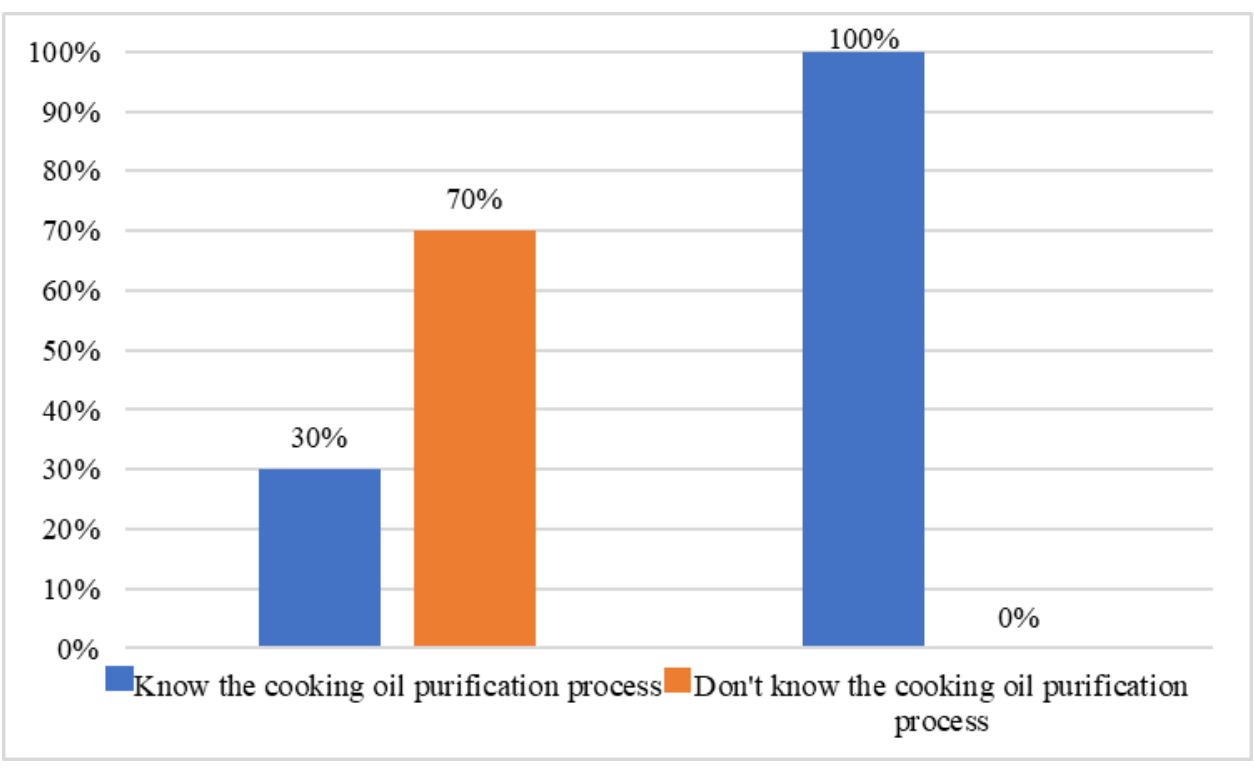

Figure 5. The results of the poll before and after the socialization event 
activities. Of the 20 respondents, $60 \%$ of them still use used cooking oil in the processing of foodstuffs that require the deep-fried method. This socialization and training activity is important to also be carried out in other places, as an extension of a healthy lifestyle for the community in general

3. The 3R (Reduce-Recycle-Reuse) pattern of waste road oil needs to be considered as an integrated activity that is integrated with each other. The cleaning activities of used cooking oil using bentonite are in the realm of recycling which in the end will still produce waste cooking oil which is not good for the environment.

4. The method of purifying used cooking oil using bentonite can be useful as an alternative to reduce the cost of daily living expenses, considering the price of palm cooking oil that fluctuates in the market, and bentonite material which is relatively affordable. The scientific background of the speaker who comes from geology and mining science makes the speaker familiar with the characteristics of the bentonite used, as a solution for reusing raw oil, in a safe way that does not endanger health.

5. The model of an integrated approach to processing used cooking oil using bentonite minerals can be replicated to other locations.

The suggestions for CS activities:

1. The purification process using bentonite material has proven to be able to change the color of the crude oil from the original dark brown to a clearer one. The level of clarity is one of the parameters of good cooking oil quality, but this needs to be validated through laboratory tests to measure saturated fatty acid levels, impurity cation levels, and water content, in order to obtain recycled clear oil that complies with health quality standards. In the future, it can be considered to add other materials such as charcoal in the purification material, to optimize the role of the adsorbent for purifying used cooking oil.

2. Practical and economical method solutions are important points needed by the community in knowledge transfer activities between academics and non-productive partners. It is necessary to think about the application of appropriate practical technology in designing purification using benthonite, so that this method is applicable and can be practiced directly using simple household appliances. In the future, the bentonite material used will be activated first as a cost efficiency strategy and optimizing the adsorption power of bentonite minerals.

3. The topic of CS should be continued with an integrated approach, the use of bentonite material in the bentonite potential area to be applied directly in the purification of bulk cooking oil in the area.

4. CS activities will be good if they are carried out in labor-intensive areas such as MSME centers or densely populated residential areas for home-scale entrepreneurs

\section{References}

Arnovia, W. (2012). Bentonit Pacitan sebagai Adsorbsen untuk Delorosasi CPO (Crude Palm Oil). Perpustakaan Universitas Airlangga, Surabaya.

Darmadinata, M., Jumaeri., \& Sulistyaningsih, T. (2019). Pemanfaatan Bentonit Teraktivasi Asam Sulfat sebagai Adsorben Anion Fosfat dalam Air. Indonesian Journal of Chemical Science, $8(1)$.

Kecamatan Kalideres Dalam Angka (Kalideres District in Figures). (2020). Badan Pusat Statistik Kota Jakarta Barat. 
Mukherjee, S. (2011). Applied Mineralogy: Applications in Industry and Environment. Springer.
Statistik Daerah Kota Jakarta Barat. (2020). Badan Pusat Statistik Kota Administrasi Jakarta Barat. 